\title{
O povo que pronuncia seu mundo: Paulo Freire e a superação da cultura do silêncio no semiárido paraibano
}

Claviano Nascimento de Sousa

Mestre em Comunicação e Culturas Midiáticas pelo Programa de Pós-Graduação em Comunicação e Culturas Midiáticas da UFPB. Membro da Rede de Educomunicadores do Nordeste e sócio da Associação Brasileira de Profissionais da Educomunicação.

E-mail: kkacademico@gmail.com

Thaynara Policarpo de Souza Gouveia

Graduada em Comunicação Social com ênfase em Educomunicaşão na UFCG. Integra a Rede de Comunicadores Populares da Articulação do Semiárido Paraibano (Asa Paraíba). E-mail: thaynarapolicarpo@gmail.com

Diogo Lopes de Oliveira

Professor de Comunicação Social da UFCG e professor permanente do Programa de Pós-Graduação em Comunicação da UFPB.

E-mail: diogo.oliveira@ufcg.edu.br

Resumo: Este estudo situa a comunicação popular e os movimentos sociais em oposição ao status quo da cultura do silêncio. Como objeto estão listadas ações do Grupo de Trabalho de Comunicação da Articulação do Semiárido (ASA) desenvolvidas entre os anos de 2020 e 2021, que fomentam a promoção do diálogo entre agricultores e agricultoras, técnicos e técnicas de organizações sociais e científicas. $\bigcirc$ objetivo deste estudo é analisar como essas práticas se convertem em força antagônica à teoria freiriana de cultura do silêncio e à força motriz para teoria da libertação com o processo de mediação contextualizado e estruturado.
Abstract: This study places popular communication and social movements in opposition to the status quo of the Culture of Silence. This article lists seven actions developed by the Working Group on Communications of the Brazilian Semi-Arid Articulation (ASA) between 2020 and 2021 encouraging dialogue between farmers and technicians from social and scientific organizations. With that, it aims to analyze how these practices become an antagonistic force to both Freire's theory of Culture of Silence and the driving force for the Liberation Theory, contextualizing
Recebido: 15/06/2021

Aprovado: 29/09/2021 
A amostra composta por sete ações desenvolvidas, aponta para resultados animadores no sentido da superação da opressão sobre o direito à práxis do diálogo e um processo de emancipação comunicativa do povo nordestino - com toda sua diversidade, modos de ser e complexidade.

Palavras-chave: movimentos sociais; articulação do semiárido; covid-19; cultura do silêncio; democracia. and structuring the mediation process. The studied actions point to encouraging results in the sense of overcoming oppression to the right to the praxis of dialogue and a process of communicative emancipation of Northeastern people - with all their complexity, diversity, and ways of being.

Keywords: social movements; semiarid articulation; COVID-19; culture of silence; democracy.

\section{INTRODUÇÃO}

Desde o início da pandemia da covid-19, declarada pela Organização Mundial da Saúde (OMS) em março de 2020, o mundo vive os efeitos de quase 4 milhões de vidas perdidas pela doença ${ }^{1}$. Esses danos fatais são ainda mais evidentes em países desiguais e governados por chefes do poder executivo de extrema direita, notadamente os Estados Unidos (até janeiro de 2021), o Brasil e a Índia - primeiro, segundo e terceiro países com mais mortes no mundo ${ }^{2}$. Todas essas nações adotaram posicionamentos negacionistas em relação à ciência e apostaram em remédios comprovadamente ineficazes para o combate ao Sars-Cov-2, vírus causador da covid-19.

No país sul-americano, são constantes os ataques a quaisquer mobilizações ou opiniões que defendam as medidas de saúde recomendadas pela OMS: uso de máscaras, distanciamento social, higienização constante das mãos e, em locais de alta incidência do vírus e ocupação de leitos, o fechamento de serviços não essenciais ${ }^{3}$. Tampouco houve campanhas nacionais de conscientização organizadas pelo Governo Federal. Os números de casos e mortes pela covid-19 são contabilizados no Brasil por um consórcio de veículos de comunicação, uma vez que não há dados oficiais fornecidos pelo Ministério da Saúde do país. Portanto, esse papel acaba sendo desempenhado por órgãos municipais e estaduais de saúde, além de ONG e entidades do terceiro setor e da sociedade civil organizada.

Em uma perspectiva mais ampla, e mesmo antes da pandemia, os movimentos conservadores que elegeram o atual presidente Jair Bolsonaro, em 2018, tentam constantemente deslegitimar o legado de Paulo Freire, pesquisador brasileiro mais estudado e citado em todo o mundo. A razão dessa perseguição ao patrono da educação brasileira é sua proposta emancipadora, empoderadora, cidadã e de valorização do pensamento crítico entre as camadas mais pobres da população. É de interesse da burguesia - responsável por fomentar o discurso de falsa dicotomia entre preservação das vidas ou a saúde da economia - que a parcela pobre da população brasileira continue invisível, oprimida e silenciada.

1. WHO CORONAVIRUS (COVID-19) Dashboard. Word Health Organization, [s. I.], 2021. Disponível em: https://COVID19.who. int/. Acesso em: 10jun. 2021. 2. SITUATION BY REGION, COUNTRY, TERRITORY \& AREA. Word Health Organization, [s. I.], 2021. Disponível em: https://COVID19. who.int/table. Acesso em: 2 maio 2021.

3. OLIVEIRA, Diogo Lopes de; MORENO, Erick; LEWENSTEIN, Bruce V. Media representations of official declarations and political actions in Brazil during the COVID-19 pandemic. Frontiers in Communication, Lausanne, v. 6, 2021. 


\section{comunicação \& educação • Ano XXVI • número 2 • jul/dez 2021}

4. SOBRE NÓS: HISTÓRIA. Articulação Semiárido Brasileiro, [s. I.], 2021. Disponível em: https://www. asabrasil.org.br/sobre-nos/ historia. Acesso em 3 maio 2021.

5. FREIRE, Paulo. Ação cultural para a libertação e outros escritos. São Paulo: Paz e Terra, 1976; Idem. Cultural freedom in Latin America. In: COLONNESE, Louis (ed.). Human rights and the liberation of man in the Americas. Notre Dame: University of Notre Dame Press, 1970; Idem. Educação como prática de liberdade. Rio de Janeiro: Paz e Terra, 1967; Idem. Extensão ou comunicação? Rio de Janeiro: Paz e Terra, 1968.
Em um cenário de omissão do Estado e para conter os prejuízos causados pela desinformação, é especialmente importante que entidades do terceiro setor produzam conteúdos em favor das recomendações de saúde pública durante a pandemia, ocupando outros espaços de formação e sistematização da palavra. É necessário ainda que esses conteúdos sejam de fácil assimilação por parte da população das pequenas cidades do interior nordestino e tenham a mesma capacidade de compartilhamento dos conteúdos falsos ou imprecisos.

Por esse motivo, a Articulação Semiárido Brasileiro (ASA) ${ }^{4}$, "uma rede que defende, propaga e põe em prática, inclusive através de políticas públicas, o projeto político da convivência com o Semiárido" e que pretende "fortalecer a sociedade civil na construção de processos participativos para o desenvolvimento sustentável e a convivência com o Semiárido referenciados em valores culturais e de justiça social", elaborou um plano de comunicação em execução desde março de 2020, que contempla as dimensões físicas e virtuais do seu território de atuação.

Foi produzido um conjunto de peças, em linguagem característica e com conteúdo formativo, sobre uma série de temas de interesse das comunidades atendidas por ações da entidade. Estas peças se somam a transmissões em plataformas de streaming acerca de tópicos como a pandemia e suas repercussões, o caráter social e econômico de políticas públicas, a construção social e comunitária de perfis para representação política nas eleições, as celebrações de datas importantes ao calendário da agroecologia e as questões de gênero.

Assim, o objeto deste estudo de caso é o conjunto de ações desencadeadas por meio do Grupo de Comunicação da Articulação do Semiárido entre 2020 e 2021. Nesse intervalo, compõem o recorte deste estudo eventos e campanhas virtuais e presenciais que tiveram foco nas mais de 300 organizações que constituem a ASA Paraíba em pelo menos 186 municípios do estado. O corpus ao qual se dedica esta investigação é formado, portanto, por sete ações de cunho político-social e sócio-organizativo que alicerçam, a partir da comunicação, as bases do trabalho da entidade.

Este estudo de caso é de caráter exploratório e relaciona os pensamentos de Paulo Freire com um conjunto de iniciativas de combate à cultura do silêncio $^{5}$ e com a proteção da população local do semiárido paraibano através do exercício da práxis da comunicação popular.

Este artigo está dividido em quatro seções, além desta introdução. Seu ponto de partida é a observação de uma construção histórico-discursiva e midiática da região Nordeste, que determinou por bastante tempo o silêncio do povo em detrimento das narrativas sistematizadas pelos invasores. Em seguida, são estabelecidas relações entre a comunicação popular, Paulo Freire e os movimentos sociais. A estreita associação entre esses elementos é abordada como resultado positivo na superação da cultura do silêncio na seção que apresenta o escopo de ações planejadas e executadas pela ASA. Por fim, as considerações finais apontam para a consolidação dos resultados da investigação e particularidades do tema estudado. 


\section{A DIMENSÃO DISCURSIVO-MIDIÁTICA DO SEMIÁRIDO}

Ao pensar o Nordeste, seja do ponto de vista histórico, ecológico ou imagético, é inevitável criar associações que remetem às características de seca, miséria e fome. Entretanto, isso não acontece por acaso. Se, por um lado, o vasto processo de colonização pelo qual passou a região nos séculos XVI e XVII, sobretudo por parte de portugueses, “[...] resultou em diferentes práticas e relações sociais, ambientais e culturais em toda a região denominada de Sertão" ; por outro, é perceptível a presença de uma abordagem maior do problema da seca e da naturalização das problemáticas sociais, como explica Maria de Lourdes Soares?.

Embora a região não tenha se esquivado das influências socioculturais, econômicas e políticas da globalização, o território ainda é marcado por aquilo que a autora trata como "rusticidade física e ecológica" ${ }^{8}$ da área sertaneja, que ainda sofre com uma estrutura agrária político-hegemônica perversa.

Toda discussão em torno dessa rusticidade foi, e ainda é, fonte da criação de paradigmas que acompanham o território, de forma mais intensa sobretudo desde o início do século XX. A lógica tecnicista de "combate à seca", implantada com a criação da Inspetoria Federal de Obras Contra as Secas (Iocs), em 1909, tinha como foco principal o armazenamento de água como forma de resolver a problemática climática e social da região ${ }^{9}$.

Conforme elucidam os pesquisadores Aldrin Martin Perez-Marin e Ana Paula Silva dos $\operatorname{Santos}^{10}$, a ocupação histórica dessa região, predominantemente composta por povos indígenas Cariris, esconde uma das maiores tragédias do processo civilizatório brasileiro. A ferrenha disputa do território por parte das comunidades indígenas e os invasores europeus, resultou em muito mais que a ocupação das terras nordestinas.

Esse processo que, por um lado, acabou aniquilando as populações tradicionais, resultou na escravidão dos povos indígenas que, num segundo momento, seriam substituídos por negros africanos ${ }^{11}$. Este cenário se torna um primeiro resquício de um processo de silenciamento do povo nordestino ${ }^{12}$ mediante a construção de um imaginário forjado, na grande maioria das vezes, pela visão do invasor.

A obra História do Cariri, de José de Figueiredo Filho ${ }^{13}$, sintetiza eventos e figuras marcantes do território nordestino, de modo particular do Cariri Cearense e pode ser utilizada como ferramenta pedagógica para explicar como essa construção imagética do Nordeste e a estruturação de um processo cultural de silenciamento desse povo ganhou força no Brasil desde a invasão do território pelos europeus, estendendo-se até os dias de hoje.

Nos aspectos de sua obra, Figueiredo Filho aponta um preconceito inaugural sofrido pelos povos Cariris, que ocuparam parte significativa do Nordeste brasileiro, a partir do seu próprio nome. O autor descreve que o nome Cariri surge da implicância de outras tribos em relação àquela que era mais fraca,
6. PEREZ-MARIN, Aldrin Martin; SANTOS, Ana Paula Silva dos. O semiárido brasileiro: riquezas, diversidades e saberes. Campina Grande: Instituto Nacional do Semiárido, 2013, p. 9.

7. SOARES, Maria de Lourdes. O sertanejo entre Deus e o Diabo na terra do sol. João Pessoa: Editora da UFPB, 2017, p. 16.

8. Ibidem, p. 17.

9. SILVA, Roberto Marinho Alves da. Entre dois paradigmas: combate à seca e convivência com o semiárido. Sociedade \& Estado, Brasília, DF, v. 18, n. 1-2, p. 361-385, 2003, p. 370.

10. PEREZ-MARIN, Aldrin Martin; SANTOS, Ana Paula Silva dos. O semiárido. Op. cit., p. 10.

11. PACHECO NETO, Manuel. A escravização indígena e o bandeirante no Brasil colonial: conflitos, apresamentos e mitos. Dourados: Ed. UFGD, 2015.

12. Ao atribuir a expressão "povo nordestino", a autora e os autores não desconsideram as características, disparidades e expressões da cultura de cada território da região Nordeste. No entanto, do ponto de vista da análise da sociedade do silêncio, o que se constata é a homogeneização do processo de silenciamento, sem considerar essas particularidades. O tratamento excludente atinge o povo nordestino em toda sua complexidade.

13. FIGUEIREDO FILHO, José de. História do Cariri. Crato: Faculdade de Filosofia, 1966. 
14. ALBUQUERQUE JÚNIOR, Durval Muniz de. A invenção do Nordeste e outras artes. Recife: Fundação Joaquim Nabuco, 1999.

15. MARTINELLO, André Souza. A invenção do Nordeste e outras artes (resenha). Revista Territórios \& Fronteiras, Cuiabá, v. 4, n. 2 p. 212-215, 2011.

16. CALLADO, Alisson Gomes. Midiatizações em territórios rurais: convivên cia com o semiárido e exclusão infocomunicacional na Paraíba. 2019. Dissertação Mestrado em Estudos da Mídia)-Universidade Federal do Rio Grande do Norte, Natal, 2019, p. 50

17. BOURDIEU, Pierre. O poder simbólico. Rio de Janeiro: Bertrand Brasil; São Paulo: Difel, 1989.

18. Teorizado por Adorno e Horkheimer, da escola de Frankfurt, a expressão "indústria cultural" fo discutida mais profundamente na obra Dialética do Esclarecimento (1944) e remete à ideia da produção cultural padronizada para consumo acrítico por parte das massas, sendo esse entendimento adotado para este trabalho.

19. Ibidem, p. 120. comunicação \& educação • Ano XXVI • número 2 • jul/dez 2021

medrosa e tola. Este discurso se consolidou ao longo do tempo, atribuindo ao povo nordestino a condição de emudecimento diante do modelo político adotado.

Um pouco mais tarde, Durval Muniz Albuquerque Jr. ${ }^{14}$ descreve de que maneira a sistematização do imaginário referente ao território corrobora para a invenção de uma parte do Brasil caricaturada e, ao mesmo tempo, separada do resto do país. A discussão ampliada por Durval Muniz evidencia que essa construção imagética da região Nordeste ganhou força entre várias classes, desde profissionais das artes até sociólogos, e culmina, atualmente, na apropriação do povo nordestino como parte da identidade cultural desses processos de "nordestinização" ${ }^{15}$ que se amparam nos meios hegemônicos de comunicação de massa.

Essa evidência dada pelos meios de comunicação à precariedade da vida no Nordeste, tratada incontáveis vezes através do flagelo do homem e da mulher do campo, na incapacidade do solo e escassez de água, acabou sendo muito bem apropriada por grupos políticos e partidários por meio daquilo que ficou conhecido como "indústria da seca". A apropriação desse discurso por grupos políticos com intenções meramente direcionadas ao exercício do poder resultou no surgimento do paradigma de "combate à seca", que focava suas ações nos efeitos e não nas causas do problema da escassez de chuvas na região Nordeste.

Ao discorrer sobre o tema, Callado ${ }^{16}$ explica que "o Nordeste não existia antes da seca, nem outras partes do seu território que não estavam inseridos no semiárido". Desse modo, a emergência da sistematização de um imaginário para esse lugar passava, à época, pela construção da ideia de devastação causada sobretudo pela cana-de-açúcar no bioma, mas também na vida do povo que ali sobrevivia.

Tal movimento sustentou, deste modo, a construção de uma narrativa unilateral que, ao mesmo tempo que ditava o que se deveria falar sobre a região, limitava o acesso à informação e silenciava o povo nordestino em relação a seus conhecimentos, demandas e cultura. No entendimento de Bourdieu ${ }^{17}$, a manutenção do discurso distorcido pela lógica do mercado e da indústria cultural $^{18}$ "funciona como um argumento que contribui - quanto mais largamente é reconhecido - para favorecer ou desfavorecer o acesso da região ao reconhecimento e, por este meio, à existência" ${ }^{19}$.

É nesse sentido que se fundamenta a crítica de Albuquerque Jr. ao tratar a representação do imaginário nordestino como uma invenção territorial, não real, protagonizada por uma elite intelectual de Recife que se sentia ameaçada pela modernidade nas artes prenunciada pelo estado de São Paulo no início dos anos 1920. 


\section{PAULO FREIRE, COMUNICAÇÃO E MOVIMENTOS SOCIAIS NO NORDESTE}

No Nordeste, em particular, o exercício de superação do paradigma de combate à seca se deu a partir da práxis comunicativa. No início dos anos 1980, o paradigma da convivência "[...] tem sua gênese nas iniciativas de centros de pesquisa, como a Embrapa, e das organizações não-governamentais que vêm desenvolvendo projetos nas áreas de recursos hídricos, produtivas e socioculturais em áreas do semi-árido brasileiro [...]"20.

Esse novo modo de conviver com as intempéries climáticas inaugura um novo paradigma que se sustenta no diálogo entre a ciência e o saber popular como estratégia para a convivência com a seca e a compreensão do bioma da Caatinga como parte da geografia da região e não como sua inimiga.

É justamente no sentido da comunicação como processo de "coparticipação dos sujeitos no ato de pensar" ${ }^{21}$ que a inauguração do novo paradigma se alinha ao pensamento freiriano. Se outrora a apresentação do cenário nordestino se dava de modo concentrado no poder de fala dos invasores, nesse novo momento, conforme preconiza Freire ${ }^{22}$, rompe-se a ideia de transmissão e fundamenta-se o diálogo no encontro entre sujeitos.

É a partir desse movimento que, de acordo com Diniz $^{23}$, em março de 1993, uma grande mobilização na sede da Superintendência do Desenvolvimento do Nordeste (Sudene), em Recife (PE), passa a exigir providências eficazes que considerassem as particularidades político-sociais e ecológicas do semiárido. Dessa mobilização surge o Fórum do Nordeste, que conta com a participação de mais de 300 entidades sociais entre representações da igreja, associações comunitárias, sindicatos rurais, entidades de cooperação internacional, movimentos de juventudes e mulheres, entre outros, que entregaram à direção do órgão uma proposta de caráter permanente com ações voltadas ao semiárido com foco na agricultura familiar, uso sustentável dos recursos naturais e democratização de políticas públicas ${ }^{24}$.

Conforme explicam Andrade e Cordeiro $\mathrm{Neto}^{25}$, o papel da igreja nesse período também ganha destaque por sua capacidade de mobilização e efetivação daquilo que Putnam ${ }^{26}$ chamou de "capital social de aproximação" ou "identidade coletiva" ${ }^{27}$, definidos por redes sociais ${ }^{28}$ de interesses e identidades similares que constituem grupos coesos e organizados.

No entendimento de Maíra Leite Escórcio e Elza Maria do Socorro Dutra ${ }^{29}$, a formação da identidade social se deu no final da década de 1990, quando foi instaurada de modo decisivo a mudança de paradigma, com "a Declaração do semiárido e o início da Articulação do Semiárido (ASA)”. Na ocasião da III Conferência das Partes da Convenção das Nações Unidas de Combate à Desertificação (COP), a organização do Fórum do Nordeste se deu de forma paralela e, a partir daquele movimento, com participação inicial de poucas dezenas de organizações, construiu a Declaração do semiárido ${ }^{30}$, que formalizou a criação da ASA como fruto da união de diversas entidades do Nordeste em
20. SILVA, Roberto Marinho Alves da. Entre dois... Op. cit., p. 376.

21. FREIRE, Paulo. Extensão... Op. cit., p. 67.

22. Ibidem, p. 69.

23. DINIZ, Paulo Cesar Oliveira. Ação coletiva e convivência com o semiárido: a experiência da articulação do semiárido paraibano. 2002. Dissertação (Mestrado em Sociologia) - Universidade Federal da Paraíba, Campina Grande, 2002; Idem. Da experimentação social ao "experimentalismo institucional": trajetórias de relações entre Estado e sociedade civil - experiências no semiárido. 2007. Tese (Doutorado em Sociologia) - Centro de Humanidades, Universidade Federal da Paraíba, Campina Grande, 2007.

24. SILVA, Roberto Marinho Alves da. Entre o combate à seca e a convivência com o semiárido: transições paradigmáticas e sustentabilidade do desenvolvimento. 2006. Tese (Doutorado em Desenvolvimento Sustentável) - Universidade de Brasília, Brasília, DF, 2006, p. 79.

25. ANDRADE, Jackeline Amantino de; CORDEIRO NETO, José Raimundo. Uma discussão sobre a possibilidade da criação institucional e sinergia entre Estado e sociedade: o caso do P1MC no semiárido brasileiro. Cadernos EBAPE. BR, Rio de Janeiro, v. 14, p. 551-568, 2016.

26. PUTNAM, Robert David. Bowling alone: the colapse and revival of American Community. Nova York: Simon and Schuster, 2000.

27. CASTELLS, Manuel. O poder da identidade. São Paulo: Paz e Terra, 1999. 
28. Castells conceitua redes sociais como "[...] redes de comunicação que envolvem a linguagem simbólica, os limites culturais, as relações de poder e assim por diante". CASTELLS, Manuel. A internet e a sociedade em Rede. In: MORAIS, Dênis de. (org.). Por uma outra comunicação: mídia, mundialização cultural e poder. Rio de Janeiro: Record, 2004, p. 94.

29. ESCÓRCIO, Maíra Leite; DUTRA, Elza Maria do Socorro. Considerações fenomenológico-exis tenciais sobre o habitar no semiárido brasileiro. Revista da Abordagem Gestáltica, Goiânia, v. 24 n. 1, p. 57-65, 2018.

30. ARTICULAÇÃO SEMIÁRIDO BRAŞILEIRO Declaração do semiárido: propostas da articulação no semiárido brasileiro para a convivência com o semiárido e o combate à desertificação. Recife: ASA, 1999.

31. LIMA, Venício A. Cultura do silêncio e democracia no Brasil: ensaios em defesa da liberdade de expressão (1980-2015). Brasília, DF: Editora UnB, 2015.

32. Ibidem, p. 30 .

33. FOUCAULT, Michel. $A$ arqueologia do saber Petrópolis: Vozes; Lisboa: Centro do Livro Brasileiro 1972, p. 43

34. HALL, Stuart. Cultura e representação. Rio de Janeiro: Ed. PUC-Rio, 2016.

35. Ibidem, p. 17

36. FREIRE, Paulo. Extensão... Op. cit., p. 66.

37. LASSWELL, Harold. The structure and function of communication in society. In: BRYSON, Lyman. The communication of ideas. New York: Institute for Religious and Social Studies, 1948.

38. KAPLÚN, Mario. El comunicador popular. Quito: Ciespal, 1985. busca de ações efetivas para a convivência com o território. Um programa de mobilização social e convivência com o semiárido acompanhava o texto da Declaração, e, mais tarde, ficaria mundialmente conhecido como Programa 1 Milhão de Cisternas (P1MC).

A essa relação entre o humano e a natureza, Freire dá o nome de práxis. Venício Lima ${ }^{31}$ destaca que "Freire se utiliza da relação do homem com a natureza para explicar o tipo de criação que é exclusivo dos seres humanos" ${ }^{2}$. Essa criação denota a capacidade crítica que se constitui no ser humano a partir, entre outros fatores, da capacidade de cocriação de mensagens oriundas dos processos de interatividade oportunizados pela comunicação.

É, portanto, na linguagem, no discurso e nas relações, presenciais ou mediadas, que se estrutura a relação do humano com o real. Em Foucault ${ }^{33}$, a noção de discurso diz respeito ao conjunto de regras históricas que, em um local e época específicos, definem a economia, a geografia ou a linguística em relação a uma área social específica, submetida a ideologias, ciência, teorias etc. Em paralelo, Hall ${ }^{34}$ reforça que a linguagem é o meio pelo qual se dá sentido às coisas e essa forma de representação "é uma das práticas centrais que produz a cultura" 35 .

O que se constata nos anos posteriores à criação da ASA é um grande processo de formação que mobiliza atores sociais em todo o Nordeste, mas de modo particular no território do semiárido. A associação foca sua ação nas práticas de convivência e inclui nessas discussões assuntos necessários para emancipação do povo e superação da cultura do silêncio, como as discussões de gênero, geração, renda, organização e, sobretudo, comunicação. Pode-se dizer que esse momento emblemático, apoiado de modo decisivo pelos governos do Partido dos Trabalhadores (PT), marca a ruptura entre as práticas políticas que evidentemente não funcionaram ao longo de mais de 100 anos e o início da construção de um novo semiárido.

No ensaio Extensão ou comunicação ${ }^{236}$, Paulo Freire reitera que o mundo em que vivemos "é um mundo de comunicação". O autor argumenta que "o mundo social humano não existiria se não fosse um mundo capaz de se comunicar". Assim, as ações adotadas pela ASA desde sua constituição convergem no sentido da superação das desigualdades sociais a partir da sistematização da práxis comunicativa na condição de tecnologia social.

Pensar ações de fins comunicativos é também pensar na relação entre emissores e receptores de informações. Inevitavelmente, a práxis do processo comunicativo perpassa outras necessidades que se estendem ao clássico paradigma teórico defendido por Harold Lasswell ${ }^{37}$. Mario Kaplún ${ }^{38}$ amplia esta discussão considerando, para tanto, uma mudança permanente de posicionamento entre emissor e receptor, de modo que se estabelece uma via de mão dupla na qual ambos os sujeitos são, ao mesmo tempo, produtores e receptores da mensagem. A relação dialógica que se forma nesse processo de cocriação da mensagem e do discurso através do ritual de interação é amplamente validado na prática da comunicação popular. 
Tratar o tema da comunicação popular, fundamentada nas experiências e cultura local, passa a ser, portanto, uma estratégia da ASA. Essa ação se complementa com processos de sistematização de experiências e de intercâmbio entre as famílias agricultoras, que promovem a construção coletiva do conhecimento e, ao mesmo tempo, um novo imaginário para o território.

Os Encontros Nacionais da Articulação Semiárido (EnconASA) colaboram no sentido da evidenciação das ações da organização nacional, mas é nas comunidades, a partir das organizações locais, que se constata o papel fundamental do movimento de convivência com a seca, preconizado pela comunicação.

\section{SUPERANDO A CULTURA DO SILÊNCIO: O TRABALHO DA ARTICULAÇÃO DO SEMIÁRIDO PARAIBANO}

A imediata mobilização dos movimentos sociais que deram origem ao Fórum Nordeste e, mais tarde, à ASA, embora a priori tenha obtido resultados limitados, ganhou força a partir da ramificação do movimento para os esta$\operatorname{dos}^{39}$. Nesta seção, portanto, concentra-se a atenção às ações desenvolvidas pela Articulação do Semiárido Paraibano no combate à cultura do silêncio.

Na Paraíba, pode-se dizer que um passo fundamental para mudança do cenário imposto pelo silenciamento do povo foi a realização, ainda em 1994, de um seminário que contou com a participação de agricultores e agricultoras, lideranças sindicais e de associações, com o tema "Semiárido Paraibano: que tipo de desenvolvimento queremos?" ${ }^{\prime 40}$.

Conforme explica Paulo Diniz,

Nessa época, a compreensão do grupo era que para pensar outro tipo de desenvolvimento, seria preciso refletir sobre o "atual modelo de desenvolvimento" esse foi o primeiro eixo de discussão do seminário. Depois, num segundo ponto, a intenção era elaborar "uma proposta de desenvolvimento para a Paraíba"

Em oposição ao que por muito tempo se estabeleceu no contexto da comunicação do Nordeste brasileiro, a realização do seminário resulta numa construção coletiva do pensar, na oportunidade de expor o pensamento. Para Freire ${ }^{42}$, a coparticipação dos sujeitos no ato de pensar se consolida através da comunicação e, portanto, seria impossível compreender o pensamento sem referência às funções cognitiva e comunicativa.

Desse modo, as ações descritas a seguir, desenvolvidas pelo Grupo de Trabalho de Comunicação da ASA Paraíba nos anos 2020 e 2021, mereceram a análise e o devido destaque não só por sua realização diante do quadro pandêmico enfrentado no Brasil, mas, sobretudo, por serem uma estratégia que se soma às demais, desenvolvidas desde os anos 1990, para superação da cultura do silêncio e emancipação do povo nordestino por meio da palavra.

39. DINIZ, Paulo Cesar Oliveira. Ação... Op. cit., p. 50. 40. Ibidem, p. 56. 41. Ibidem, p. 56. 42. FREIRE, Paulo. Extensão... Op. cit. p. 68-69. 


\section{comunicação \& educação • Ano XXVI • número 2 • jul/dez 2021}

As ações aqui analisadas estão compreendidas entre março de 2020 e maio de 2021. Neste recorte, as análises estão focadas em sete ações, conforme detalhamento desenvolvido a seguir.

\subsection{Fortalecimento do Programa de Aquisição de Alimentos (PAA).}

Além de assumir a campanha nacional promovida pela Articulação Nacional de Agroecologia (ANA), a ASA levou a cabo ações de incidência política, nas quais a expressão maior foi a realização de audiências públicas ${ }^{43}$ entre os movimentos sociais e o Conselho Estadual de Segurança Alimentar e Nutricional (Consea), com a participação dos parlamentares do campo progressista da Paraíba.

Durante todo o ano de 2020, foi criado um canal de diálogo com os parlamentares no estado, com o intuito de debater as políticas públicas voltadas para a agricultura familiar e a agroecologia. As sessões virtuais foram transmitidas pelo canal da ASA Paraíba no YouTube.

No entendimento de Venício Lima,

A concepção implícita de liberdade na definição dialógica de comunicação elaborada por Freire é constitutiva de uma cidadania ativa que equaciona autogoverno com participação política, contrariamente à liberdade negativa do liberalismo clássico, ainda hoje indissociável da retórica histórica das elites brasileiras ${ }^{44}$.

Conforme destaca Lima ${ }^{45}$, a defesa mais relevante acerca da dimensão política da comunicação feita por Freire está presente na obra Pedagogia do oprimido e se consolida no contexto que denomina ação cultural revolucionária. Assim, ao atribuir a práxis comunicativa como exercício crítico e a palavra como essência do diálogo, Freire apresenta uma interação profunda entre a reflexão e a ação ${ }^{46}$. Notadamente, em Pedagogia do oprimido ${ }^{47}$, Paulo Freire destaca que "não há palavra verdadeira que não seja ao mesmo tempo práxis. Assim, dizer a palavra verdadeira é transformar o mundo".

43. Disponivel em: https:// www.youtube.com/watch? $\mathrm{v}=6 \mathrm{FvPNFaBrPO}$. Acesso em: 30 nov. 2021

44. LIMA, Venício A. Cultura... Op. cit., p. 43.

45. Ibidem, p. 36.

46. Ibidem, p. 37.

47. FREIRE, Paulo. Ação.. Op. cit., p. 91.

\subsection{Interiorização da covid-19.}

Diante da rápida interiorização da doença provocada pelo novo coronavírus, debateu-se a situação e a circulação de desinformação sobre o contágio e a prevenção da covid-19. O tema impulsionou o Grupo de Trabalho de Comunicação da ASA Paraíba a produzir a zapnovela Conversa de cumadi e cumpadi nove áudios com linguagem informal para serem difundidos, via WhatsApp, entre as famílias acompanhadas pelas organizações da rede sobre o processo de contaminação pelo vírus. O material foi construído coletivamente com participação de jovens, agricultores e agricultoras, técnicos e técnicas dos diversos territórios da ASA Paraíba. 
O povo que pronuncia seu mundo

- Claviano Nascimento de Sousa, Thaynara Policarpo de Souza Gouveia e Diogo Lopes de Oliveira

Tabela 1: Episódios, datas e links de acesso aos programas Conversa de cumadi e cumpadi

\begin{tabular}{|c|c|c|}
\hline Nome do episódio & Data de divulgação & Link de acesso \\
\hline $\begin{array}{l}\text { Episódio } 1 \text { - Coronavírus } \\
\text { né brincadeira não! }\end{array}$ & 19 de maio de 2020 & $\begin{array}{c}\text { https://www.youtube.com/ } \\
\text { watch?v=KHGCGHSyZKU\&t=11s }\end{array}$ \\
\hline $\begin{array}{l}\text { Episódio } 2 \text { - Como utilizar } \\
\text { as máscaras de proteção }\end{array}$ & 22 de maio de 2020 & $\begin{array}{c}\text { https://www.youtube.com/watch?v=- } \\
\text { bZVtOYNiGc }\end{array}$ \\
\hline $\begin{array}{c}\text { Episódio } 3 \text { - Cada um/a } \\
\text { nas suas casas }\end{array}$ & 26 de maio de 2020 & $\begin{array}{l}\text { https://www.youtube.com/ } \\
\text { watch?v=7mbNlzRqZj8 }\end{array}$ \\
\hline $\begin{array}{c}\text { Episódio } 4 \text { - Cuidados } \\
\text { dentro de casa }\end{array}$ & 29 de maio de 2020 & $\begin{array}{l}\text { https://www.youtube.com/ } \\
\text { watch?v=TTz85qybwgg }\end{array}$ \\
\hline $\begin{array}{c}\text { Episódio } 5 \text { - Tem gente } \\
\text { voltando de viagem }\end{array}$ & 5 de julho 2020 & https://youtu.be/TOjBFXzHtBU \\
\hline $\begin{array}{c}\text { Episódio } 6 \text { - Dividir tarefas } \\
\text { também é questão de } \\
\text { saúde }\end{array}$ & 9 de junho de 2020 & $\begin{array}{c}\text { https://www.facebook. } \\
\text { com/306856726186497/ } \\
\text { videos/332412257745278 }\end{array}$ \\
\hline $\begin{array}{c}\text { Episódio } 7 \text { - Auxílio } \\
\text { emergencial }\end{array}$ & 16 de junho de 2020 & $\begin{array}{c}\text { https://www.facebook. } \\
\text { com/306856726186497/ } \\
\text { videos/269079950964112 }\end{array}$ \\
\hline $\begin{array}{c}\text { Episódio } 8 \text { - Fortalecendo } \\
\text { a imunidade }\end{array}$ & 21 de junho de 2020 & $\begin{array}{c}\text { https://www.facebook. } \\
\text { com/306856726186497/ } \\
\text { videos/914903035641222 }\end{array}$ \\
\hline $\begin{array}{l}\text { Episódio } 9 \text { - Preciso ir } \\
\text { na rua, e agora? }\end{array}$ & 30 de junho de 2020 & $\begin{array}{l}\text { https://www.instagram.com/tv/ } \\
\text { CCEq5nxHI4B/ }\end{array}$ \\
\hline
\end{tabular}

A série Conversa de cumadi e cumpadi utiliza aspectos próprios da comunicação nordestina no semiárido como sotaque, palavras e expressões do cancioneiro popular para fomentar o diálogo dos capítulos entre si e destes produtos com o público do semiárido paraibano. É como se os conteúdos falsos e desinformativos compartilhados como rastro de pólvora nas redes sociais de todo o país encontrassem seu antídoto local na série que pretende provocar reflexão, diálogo e compreensão dos riscos da pandemia da covid-19, especialmente para as populações historicamente excluídas, a partir de conteúdos representativos da cultura local.

A propaganda, os slogans, os "depósitos", os mitos são instrumentos usados pelo invasor para lograr seus objetivos: persuadir os invadidos de que devem ser objetos de sua ação, de que devem ser presas dóceis de sua conquista. Daí ser necessário ao invasor descaracterizar a cultura invadida, romper seu perfil, enchê-la inclusive de subprodutos da cultura inovadora ${ }^{48}$.

Além disso, o fato de os conteúdos terem sido construídos coletivamente com a participação de jovens, agricultores e agricultoras, técnicos e técnicas dos diversos territórios da ASA Paraíba carrega um outro ponto: a união de saberes locais com o conhecimento técnico torna o material produzido ainda mais potente.

48. FREIRE, Paulo. Extensão... Op. cit., p. 32. 


\section{comunicação \& educação • Ano XXVI • número 2 • jul/dez 2021}

\subsection{Violência contra mulher.}

Para o tratamento dessa temática, a ASA somou-se à iniciativa da Campanha Pela Justa Divisão do Trabalho Doméstico, promovida pela Rede Feminismo e Agroecologia e, em 7 de agosto de 2020, dia em que a Lei Maria da Penha completou 14 anos, o GT de Mulheres e Agroecologia da ASA Paraíba realizou a live "Ficar em casa é questão de saúde. Dividir tarefas e viver sem violência também" ${ }^{\prime 9}$ para debater os impactos da pandemia na vida das mulheres do campo e da cidade.

A ASA Paraíba, assim como os territórios que a compõem, seguiu circulando o material produzido pela campanha em suas redes sociais e nos grupos de WhatsApp. Nesse sentido, a efetivação de uma cultura de libertação, neste caso em específico da figura feminina, se dá, mais uma vez, através da práxis do diálogo. Com efeito, Freire destaca que o diálogo é "um comportamento humano que envolve ação e reflexão, [...] é o direito de expressar-se e expressar o mundo, de criar e recriar, de decidir, de optar" ${ }^{50}$.

Na obra Sem ódio nem violência, J. Simões Jorge ${ }^{51}$ ressalta as premissas da teoria da libertação de Paulo Freire. O autor destaca que a doutrina para a libertação, defendida por Freire, não se pauta na guerra, na luta armada ou em revoluções sangrentas, mas no viés profundamente humanizado, através do qual a libertação está totalmente voltada para o humano e para a humanização de regimes de opressão ${ }^{52}$.

49. Disponível em: https://www.facebook. $\mathrm{com} / 306856726186497$ videos/3660437510634270. Acesso em: 30 nov. 2021.

50. Idem. Ação... Op. cit., p. 49.

51. JORGE, J. Simões. Sem ódio nem violência. São Paulo: Loyola, 1979.

52. Ibidem, p. 13

53. Disponível em: ht tps://www.facebook. com/ASA-Para\%C3\%ADba-306856726186497/ photos/pcb.128758684144 6809/1287586678113492/ Acesso em: 30 nov. 2021.

54. Disponível em: https:// www.youtube.com/watch? $v=z s d l 1 j h Z A V Q$. Acesso em: 30 nov. 2021

55. GONÇALVES, Alexandre Oviedo; ABDALA, Mônica Chaves. "Na banca do 'Seu' Pedro é tudo mais gostoso": pessoalidade e sociabilidade na feira-livre. Ponto Urbe, São Paulo v. 12, p. $1-14,2013$, p. 3.

\subsection{Semana dos Orgânicos.}

Diante da pandemia, não foi possível a realização presencial das ações da tradicional Semana dos Orgânicos, uma iniciativa do Grupo de Trabalho Comercialização da ASA Paraíba e dos integrantes da Comissão de Produção Orgânica da Paraíba (CPOrg), como a Feira Regional de Produtos Agroecológicos que acontece desde 2018 na Praça da Bandeira, em Campina Grande.

As ações foram virtuais, com a produção de peças gráficas ${ }^{53}$ de divulgação dos espaços agroecológicos de comercialização e a produção de vídeos ${ }^{54} \mathrm{com}$ a participação dos produtores. A ideia foi fortalecer a venda porta a porta e nas feiras agroecológicas que estavam em funcionamento durante a pandemia.

Esses espaços de comercialização estendem sua característica social ao assumirem o papel de espaços de sociabilidades, marcados não só pela venda e compra de mercadorias, mas pela possibilidade de agregar "sentimentos, significados e hábitos engendrados no 'bate-papo e na conversa-fiada' entre aqueles que a frequentam" ${ }^{55}$.

As feiras na praça central de Campina Grande são espaços importantes de diálogo com a sociedade sobre a importância dos alimentos saudáveis, livres de transgênicos e agrotóxicos, além de possibilitar o acesso da comunidade urbana, mesmo que pontual, aos produtos. 


\subsection{Semana Mundial da Alimentação.}

Impossibilitados de organizar a Feira Agroecológica realizada todos os anos na semana da Alimentação, o Centro de Ação Cultural (Centrac), o Fórum Paraibano de Soberania e Segurança Alimentar e Nutricional (FPBSSAN), a ASA Paraíba, a Plataforma Mercosul Social e Solidário (PMSS) e o Consea realizaram uma exposição de cartazes na Praça da Bandeira, em Campina Grande, com o tema "O Brasil tem fome!".

Pensar o direito à alimentação num país como o Brasil é, sem dúvidas, pensar em liberdade. A representação da opressão no gesto de protestar estabelece o espaço para amplas reflexões. Conforme explica Freire, a opressão "se constitui em um ato proibitivo do ser mais dos homens" ${ }^{56}$. No entendimento do autor, a liberdade é uma conquista, e se difere da doação pela exigência de uma busca permanente que se efetiva na ação responsável de quem a faz existir ${ }^{57}$.

Dessa maneira, a ação realizada em alusão à semana mundial de alimentação se deu por meio da utilização de cartazes que foram espalhados em praça pública durante a manhã do dia 16 de outubro. Nesta exposição, aconteceu um ato de protesto silencioso e resguardando os protocolos de segurança estabelecidos em virtude da pandemia da covid-19.

\subsection{Campanha "Não troque seu voto".}

A campanha "Não troque seu voto" consistiu em uma ação da ASA que se estendeu a todas as organizações que a compõem com o objetivo de estimular o voto consciente. A campanha foi direcionada, especialmente, para as famílias que experimentaram a inclusão social por meio de um conjunto de políticas e programas públicos voltados para a agricultura familiar e para o fortalecimento da convivência com o semiárido.

Do ponto de vista político, a criação de cenário de representação forjado na superação à falta de água para o abastecimento favoreceu de modo decisivo a manutenção do modelo de gestão baseado no combate à seca, que mais tarde seria denunciado por Antônio Callado ${ }^{58}$, caracterizando as políticas de Estado como indústria da seca, que, no entanto, continua favorecendo nos dias de hoje a pseudo-dependência do Nordeste em relação às regiões Sul e Sudeste. A ideia de desenvolvimento adotada por José de Souza Silva ${ }^{59}$ descreve justamente como o vértice criado por esse cenário tenta e consegue distinguir entre superiores e inferiores os territórios nacionais, ao passo que os divide em desenvolvidos e subdesenvolvidos.

Apoiando-se no modelo das comunidades agrárias europeias, através das quais o povo exercia seu papel de cidadania participando decisivamente no poder local, Freire reforça, em sua obra Educação como prática da liberdade, que:

56. FREIRE, Paulo. Pedagogia do Oprimido. Rio de Janeiro: Paz e Terra, 1977, p. 47

57. Ibidem, p. 35.

58. CALLADO, Antônio. Os industriais da seca e os "galileus" de Pernambuco. Rio de Janeiro: Civilização Brasileira, 1960.

59. SILVA, José de Souza. Aridez mental, problema maior: contextualizar a educação para construir o 'dia depois do desenvolvimento' no semiárido brasileiro. Campina Grande: Embrapa/INSA, 2010. 
O Brasil nunca experimentou aquele senso de comunidade, de participação na solução de problemas comuns [...] senso que se instala na consciência do povo e se transforma em sabedoria democrática ${ }^{60}$.

O Grupo de Comunicação da ASA Paraíba se envolveu sobretudo na produção do que se passou a chamar zapnovelas, elaborando os roteiros e trilhas sonoras para a ampla divulgação nas redes sociais. O teor central do conteúdo abordado nessa ação consistiu justamente na ideia de organização comunitária para definição de representantes políticos capazes de atender às demandas das comunidades rurais.

O conteúdo remete a uma reflexão sobre o tipo de representante que o povo camponês deseja para ocupar um cargo no poder executivo e legislativo de seus municípios. A narrativa, protagonizada por agricultores e agricultoras lideranças de comunidades camponesas rurais, sustenta-se naquilo que Freire denunciava como uma "enfermidade" do povo, a ausência de voz, e se consolida na emergência da fala como superação do silêncio. A Tabela 2 descreve o teor dos conteúdos da série.

\section{Tabela 2: Campanha "não troque seu voto"}

\begin{tabular}{|c|c|c|c|}
\hline $\begin{array}{l}\text { Nome do } \\
\text { episódio }\end{array}$ & $\begin{array}{l}\text { Data de } \\
\text { divulgação }\end{array}$ & Link de acesso & Palavras-chave \\
\hline $\begin{array}{l}\text { Episódio } 1 \text { - } \\
\text { Campanha na } \\
\text { comunidade } \\
\text { (parte 1) }\end{array}$ & $\begin{array}{l}1 \text { de outubro } \\
\text { de } 2020\end{array}$ & $\begin{array}{l}\text { https://www.instagram.com/ } \\
\text { tv/CFzXH8DHVq1/ }\end{array}$ & $\begin{array}{l}\text { campanha eleitoral; } \\
\text { consciência cidadã; } \\
\text { democracia; senso crítico. }\end{array}$ \\
\hline $\begin{array}{l}\text { Episódio } 2 \text { - } \\
\text { Campanha na } \\
\text { comunidade } \\
\text { (parte 2) }\end{array}$ & $\begin{array}{l}9 \text { de outubro } \\
\text { de } 2020\end{array}$ & $\begin{array}{l}\text { https://www.instagram.com/ } \\
\text { tv/CGIIC4wnOrq/ }\end{array}$ & $\begin{array}{l}\text { representatividade; } \\
\text { igualdade de gênero; } \\
\text { identidade comunitária; } \\
\text { exercício } \\
\text { da cidadania. }\end{array}$ \\
\hline $\begin{array}{l}\text { Episódio } 3 \text { - } \\
\text { O mandato do } \\
\text { seu vereador/a } \\
\text { também é seu }\end{array}$ & $\begin{array}{l}20 \text { de outubro } \\
\text { de } 2020\end{array}$ & $\begin{array}{l}\text { https://www.instagram.com/ } \\
\text { tv/CGk64adnwNF/ }\end{array}$ & $\begin{array}{l}\text { câmara municipal; proposta } \\
\text { de lei; representação } \\
\text { política; ciclo de } \\
\text { política pública. }\end{array}$ \\
\hline $\begin{array}{l}\text { Episódio } 4 \text { - Já } \\
\text { perdeu seu valor } \\
\text { (parte 1) }\end{array}$ & $\begin{array}{l}26 \text { de novembro } \\
\text { de } 2020\end{array}$ & $\begin{array}{l}\text { https://www.instagram.com/ } \\
\text { tv/CIDula3HL35/ }\end{array}$ & $\begin{array}{l}\text { valor do voto; compra/ } \\
\text { venda de voto; consciência } \\
\text { política. }\end{array}$ \\
\hline $\begin{array}{l}\text { Episódio } 5 \text { - Já } \\
\text { perdeu seu valor } \\
\text { (parte 2) }\end{array}$ & $\begin{array}{l}26 \text { de novembro } \\
\text { de } 2020\end{array}$ & $\begin{array}{l}\text { https://www.instagram.com/ } \\
\text { tv/CIDwlLPnbHr/ }\end{array}$ & $\begin{array}{l}\text { valor do voto; compra/ } \\
\text { venda de voto; } \\
\text { consciência política. }\end{array}$ \\
\hline $\begin{array}{l}\text { Episódio } 6 \text { - Diz } \\
\text { aí juventude }\end{array}$ & $\begin{array}{l}26 \text { de novembro } \\
\text { de } 2020\end{array}$ & $\begin{array}{l}\text { https://www.instagram.com/ } \\
\text { tv/CIDwjYWnr6h/ }\end{array}$ & $\begin{array}{l}\text { renovação política; } \\
\text { representatividade; minorias. }\end{array}$ \\
\hline $\begin{array}{l}\text { Episódio } 7 \text { - Um } \\
\text { voto de qualidade }\end{array}$ & $\begin{array}{l}26 \text { de novembro } \\
\text { de } 2020\end{array}$ & $\begin{array}{l}\text { https://www.instagram.com/ } \\
\text { tv/CIDwxyUH6gJ/ }\end{array}$ & $\begin{array}{l}\text { política pública; cultura } \\
\text { local; conjuntura política. }\end{array}$ \\
\hline
\end{tabular}


Os episódios da série circularam no Facebook e Instagram da ASA, mas também se espalharam nas páginas oficiais das organizações que compõem a entidade e, de modo mais efetivo, emdiversos grupos de WhatsApp em todo semiárido nordestino.

\subsection{Semiárido pela vacina.}

A campanha mais recente, e ainda em curso, do Grupo de Trabalho de Comunicação da ASA diz respeito à vacinação contra a covid-19. Considerando o aspecto de um processo formativo sobre a vacinação que teve início em 2021, a desmistificação e superação da desinformação são as ferramentas usadas pela ASA para chegar às comunidades rurais do semiárido paraibano.

Nesta ação, além da já tradicional zapnovela e das imagens que circulam nas redes sociais acerca do tema, o material produzido ganhou uma nova plataforma de circulação. Entrevistas com especialistas foram realizadas e disponibilizadas em formato podcast acessíveis em plataformas gratuitas.

A Tabela 3 mostra os episódios que compunham a campanha até maio de 2021.

\section{Tabela 3: Semiárido pela vacina}

\begin{tabular}{c|c|c|c}
\hline Nome do episódio & Data de divulgação & Links de acesso & Palavras-chave \\
\hline $\begin{array}{c}\text { Episódio 1 - } \\
\text { ASA pela vacina }\end{array}$ & 8 de abril de 2021 & $\begin{array}{c}\text { https://www. } \\
\text { instagram.com/tv/ } \\
\text { CNawT16BkzM/ }\end{array}$ & $\begin{array}{c}\text { desinformação; } \\
\text { vacina; ciência; } \\
\text { divulgação científica. }\end{array}$ \\
\hline $\begin{array}{c}\text { Episódio 2 - } \\
\text { Mais vacinas! }\end{array}$ & 22 de abril de 2021 & $\begin{array}{c}\text { https://www. } \\
\text { instagram.com/ } \\
\text { tv/CN-pdePHtwh/ }\end{array}$ & $\begin{array}{c}\text { campanha de vacinação; } \\
\text { percentual de vacinados; } \\
\text { imunização em massa. }\end{array}$ \\
\hline $\begin{array}{c}\text { Episódio 3 - Kit } \\
\text { covid não serve }\end{array}$ & 17 de maio de 2021 & $\begin{array}{c}\text { https://www. } \\
\text { instagram.com/tv/ } \\
\text { CO-R9F2hO7Q/ }\end{array}$ & $\begin{array}{c}\text { kit covid; uso de máscaras; } \\
\text { desinformação; } \\
\text { divulgação científica. }\end{array}$ \\
\hline
\end{tabular}

Fonte: Elaboração própria.

Além dos episódios temáticos, estão disponíveis no Spotify entrevistas com especialistas, poesias e causos. Mais uma vez, se consolida a construção de um cenário de superação da desinformação e protagonismo comunicativo no qual homens e mulheres podem ter seu direito de fala e crítica disponibilizados.

\section{CONSIDERAÇÕES FINAIS}

A inegável escolha de Paulo Freire pelos oprimidos se alinha com a ação dos movimentos sociais no que se refere à superação de desigualdades. Assim, ganham destaque aquelas que se relacionam com o direito à informação e à comunicação, assegurados por leis no Brasil, ancorado no paradigma da comunicação dialógica e da superação da cultura do silêncio. 
Apesar da pouca capacidade instalada e dos poucos profissionais de comunicação que permaneceram nas instituições que fazem a ASA, o planejamento e a vocação para o trabalho coletivo são partes significativas da atuação da rede de comunicadores populares da associação.

Convém atentar-se ao fato de que a pandemia da covid-19 limitou em medida considerável o trabalho da ASA. Pensar na inclusão mais ampla do povo do campo é pensar, também, que parte considerável dessa população não tem acesso a telefonia e internet de qualidade e que as discussões sobre diversos temas neste território se dão através da interação direta face a face.

No entanto, os espaços e canais de comunicação disponíveis têm sido ocupados em um movimento que assegura a disseminação de informações e conteúdos idealizados e produzidos por aqueles que, de fato, conhecem a realidade local. Nesta situação, a tecnologia é o desafio a ser superado, e a juventude tem papel fundamental na disseminação do discurso sobre o semiárido, dada sua maior habilidade com as novas tecnologias da comunicação e informação.

Os resultados mostram que conteúdos educativos, curtos e de fácil replicação nas redes sociais, atrelados ao exercício do diálogo, têm a capacidade de servir como antídoto a conteúdos falsos e de fortalecer a percepção e valor cultural em regiões rurais da Paraíba. Ao todo, foram alcançados pelas ações comunicativas da ASA Paraíba, descritas neste trabalho, ao menos 186 dos 223 municípios paraibanos e cerca de 300 organizações.

A união de profissionais de comunicação e famílias agricultoras resulta ainda no encontro de um povo com coragem e capacidade de apresentar-se, integrar-se, incluir-se e refletir sobre o processo de construção cultural do Nordeste brasileiro. Essa evolução histórica é marcada por disputas de narrativas, de acesso e de poder, mas tem sido superada a partir do pleno exercício do diálogo.

\section{REFERÊNCIAS BIBLIOGRÁFICAS}

ALBUQUERQUE JÚNIOR, Durval Muniz de. A invenção do Nordeste e outras artes. Recife: Fundação Joaquim Nabuco, 1999.

ANDRADE, Jackeline Amantino de; CORDEIRO NETO, José Raimundo. Uma discussão sobre a possibilidade da criação institucional e sinergia entre Estado e sociedade: o caso do P1MC no semiárido brasileiro. Cadernos EBAPE.BR, Rio de Janeiro, v. 14, p. 551-568, 2016.

ARTICULAÇÃO SEMIÁRIDO BRASILEIRO. Declaração do semiárido: propostas da articulação no semiárido brasileiro para a convivência com o semiárido e o combate à desertificação. Recife: ASA, 1999.

BOURDIEU, Pierre. O poder simbólico. Rio de Janeiro: Bertrand Brasil; São Paulo: Difel, 1989. 
CALLADO, Alisson Gomes. Midiatizações em territórios rurais: convivência com o semiárido e exclusão infocomunicacional na Paraíba. 2019. Dissertação (Mestrado em Estudos da Mídia) - Universidade Federal do Rio Grande do Norte, Natal, 2019.

CALLADO, Antônio. Os industriais da seca e os "galileus" de Pernambuco. Rio de Janeiro: Civilização Brasileira, 1960.

CASTELLS, Manuel. O poder da identidade. São Paulo: Paz e Terra, 1999.

CASTELLS, Manuel. A internet e a sociedade em Rede. In: MORAIS, Dênis de. (org.). Por uma outra comunicação: mídia, mundialização cultural e poder. Rio de Janeiro: Record, 2004.

DINIZ, Paulo Cesar Oliveira. Ação coletiva e convivência com o semiárido: a experiência da articulação do semiárido paraibano. 2002. Dissertação (Mestrado em Sociologia) - Universidade Federal da Paraíba, Campina Grande, 2002.

DINIZ, Paulo Cesar Oliveira. Da experimentação social ao "experimentalismo institucional": trajetórias de relações entre Estado e sociedade civil experiências no semiárido. 2007. Tese (Doutorado em Sociologia) Universidade Federal da Paraíba, Campina Grande, 2007.

ESCÓRCIO, Maíra Leite; DUTRA, Elza Maria do Socorro. Considerações fenomenológico-existenciais sobre o habitar no semiárido brasileiro. Revista da Abordagem Gestáltica, Goiânia, v. 24, n. 1, p. 57-65, 2018.

FIGUEIREDO FILHO, José de. História do Cariri. Crato: Faculdade de Filosofia, 1966.

FOUCAULT, Michel. A arqueologia do saber. Petrópolis: Vozes; Lisboa: Centro do Livro Brasileiro, 1972.

FREIRE, Paulo. Educação como prática de liberdade. Rio de Janeiro: Paz e Terra, 1967.

FREIRE, Paulo. Extensão ou comunicação? Rio de Janeiro: Paz e Terra, 1968.

FREIRE, Paulo. Cultural freedom in Latin America. In: COLONNESE, Louis (ed.). Human rights and the liberation of man in the Americas. Notre Dame: University of Notre Dame Press, 1970.

FREIRE, Paulo. Ação cultural para a libertação e outros escritos. São Paulo: Paz e Terra, 1976.

FREIRE, Paulo. Pedagogia do oprimido. Rio de Janeiro: Paz e Terra, 1977.

GONÇALVES, Alexandre Oviedo; ABDALA, Mônica Chaves. "Na banca do 'Seu' Pedro é tudo mais gostoso": pessoalidade e sociabilidade na feira-livre. Ponto Urbe, São Paulo, v. 12, p. 1-14, 2013. 
comunicação \& educação • Ano XXVI • número 2 • jul/dez 2021

HALL, Stuart. Cultura e representação. Rio de Janeiro: Ed. PUC-Rio, 2016.

JORGE, J. Simões. Sem ódio nem violência. São Paulo: Loyola, 1979.

KAPLÚN, Mario. El comunicador popular. Quito: Ciespal, 1985.

LASSWELL, Harold. The structure and function of communication in society. In: BRYSON, Lyman (ed.). The communication of ideas. New York: Institute for Religious and Social Studies, 1948.

LIMA, Venício A. Cultura do silêncio e democracia no Brasil: ensaios em defesa da liberdade de expressão (1980-2015). Brasília, DF: Editora UnB, 2015.

MARTINELLO, André Souza. A invenção do Nordeste e outras artes (resenha). Revista Territórios \& Fronteiras, Cuiabá, v. 4, n. 2, p. 212-215, 2011.

OLIVEIRA, Diogo Lopes de; MORENO, Erick; LEWENSTEIN, Bruce V. Media representations of official declarations and political actions in Brazil during the COVID-19 pandemic. Frontiers in Communication, Lausanne, v. 6, 2021.

PACHECO NETO, Manuel. A escravização indígena e o bandeirante no Brasil colonial: conflitos, apresamentos e mitos. Dourados: Ed. UFGD, 2015.

PEREZ-MARIN, Aldrin Martin; SANTOS, Ana Paula Silva dos. O semiárido brasileiro: riquezas, diversidades e saberes. Campina Grande: Instituto Nacional do Semiárido, 2013.

PUTNAM, Robert David. Bowling alone: the colapse and revival of American Community. Nova York: Simon and Schuster, 2000.

SILVA, José de Souza. Aridez mental, problema maior: contextualizar a educação para construir o 'dia depois do desenvolvimento' no semiárido brasileiro. Campina Grande: Embrapa/INSA, 2010.

SILVA, Roberto Marinho Alves da. Entre dois paradigmas: combate à seca e convivência com o semiárido. Sociedade \& Estado, Brasília, DF, v. 18, n. 1-2, p. 361-385, 2003.

SILVA, Roberto Marinho Alves da. Entre o combate à seca e a convivência com o semiárido: transições paradigmáticas e sustentabilidade do desenvolvimento. 2006. Tese (Doutorado em Desenvolvimento Sustentável) Universidade de Brasília, Brasília, DF, 2006.

SITUATION BY REGION, COUNTRY, TERRITORY \& AREA. Word Health Organization, [s.l.], 2021. Disponível em: https://COVID19.who.int/table. Acesso em: 2 maio 2021.

SOARES, Maria de Lourdes. O sertanejo entre Deus e o Diabo na terra do sol. João Pessoa: Editora da UFPB, 2017. 
O povo que pronuncia seu mundo

- Claviano Nascimento de Sousa, Thaynara Policarpo de Souza Gouveia e Diogo Lopes de Oliveira

SOBRE NÓS: HISTÓRIA. Articulação Semiárido Brasileiro, [s. l.], 2021. Disponível em: https://www.asabrasil.org.br/sobre-nos/historia. Acesso em: 3 maio 2021.

WHO CORONAVIRUS (COVID-19) Dashboard. Word Health Organization, [s. l.], 2021. Disponível em: https:/ /COVID19.who.int/. Acesso em: 10 jun. 2021. 